\title{
Internet + Talent Training Base Construction for Integration of Medical Treatment, Nursing and Elderly Care
}

\author{
Liu Libing , Xue Xin, Hei Yihong, Yang Rui \\ Medical College, Peihua University, Xi'an, China 357435305@qq.com, \\ 815724264@qq.com, 110484104@qq.com,1404131647@qq.com
}

Keywords:Internet+; endownment; medicalcare personnel; cultivating mode

\begin{abstract}
With the advent of the global aging society, the demand of the global high-quality team of old-age care professionals is increasing. Therefore, we constructed an Internet + talent training base of integration of medical treatment, nursing and elderly care so as to provide a good platform for students in medical schools with gerontology and geriatric nursing theory teaching and practical training, and as well as standardized professional training platform for the nursing staffs working in nursing institutions for the aged and medical staffs working in elderly medical institutions. By combining theoretical teaching and practical teaching together, practical training base and practice base together, academic education and vocational education together, multiple training ways are applied to develop multilevel elderly medical workers with the Internet background, providing a new thought for the cultivation of elderly medical qualified personnel in the Internet age, and also providing a new way for the employment of higher vocational students majoring in medical science, which enjoys a hopeful prospect.
\end{abstract}

\section{Introduction}

Along with the accelerating aging of population, the old-aging support problem becomes increasingly prominent. The aging of the population is the major social problems of the $21 \mathrm{st}$ century as well as the hot spot in the whole society. And the population of elder people accounted for $15.5 \%$ of the total population of the society [1] and in 2020 it will amount to 2043 million. In 2025, it will exceed 300 million [2]. According to prediction, by 2040, China's aging population will increase to 374 million, accounting for $24.48 \%$ of the total population, reaching the aging peak [3]. Our country is the only one that the elderly population is over 100 million. But there is only 11.6 beds per thousand of the elderly of our country's endowment institution. From nursing services aspect, nursing staff in our country no matter from the quantity or quality can not meet the needs of social development[4].

As the increasing population of aging and disability, there is a dire need in the health care such as elderly preventive care, disease nursing, chronic disease management, long-term care. Hence it requires great challenge in the elderly health care personnel quantity, knowledge and ability. As the weakening of traditional home care, a sharply increasing demand of aging care nurses begin to flourish. However, Elderly medical and nursing personnel training development in our country is still at an initial stage. The aged care professional development relatively lag behind. Nurses in hospitals, communities and nursing institutions are all from common nursing schools, without receiving systematic geriatric nursing education[5].

The main sources of the personnel engaged in old-age care in our country are ordinary nurses in hospitals and nursing workers. Ordinary nurses focus on the old man disease care, which can't be fully focused on life and spiritual needs. Workers who are lack of medical knowledge and with a lower education degree only pay attention to the service of nanny, not caring for the elderly health assessment and physical health care. The two kinds of nursing personnel are not comprehensively qualified to old-age care in theoretic knowledge, and not meeting the elderly people's need in life, spiritual and medical treatment. To develop the old-age care in China, except improving old-age nursing staff's quality in an overall way, we still need 
to set up the old nurse admittance qualification system and clarify the qualification requirements, knowledge skills. Furthermore, to improve the quality of the aged care is particularly crucial. In the process of investigation, the Percentage of certificate keeper who engaged in old-age care is not high. For example, Beijing and Shanghai city nursing home nurses' percentage of certificate keeper is 57 . $14 \%$. Percentage of certificate keeper for old people care is lower in other small and medium-sized city. [6]

The current old-age nursing education in colleges and universities is far from enough. Professional nurses with nursing knowledge of old-age care can not satisfy the needs of society. Cultivating highly-level professionals is urgent. Drawing lessons from the domestic and foreign advanced experience and carrying professional construction work of elderly services are important ways in the construction of the elderly maintenance personnel[7]. In 2006, the State Council issued the opinions about speeding up the development of pension services, pointing out that we need to speed up the training of specialists in the field of nursing and so on, to establish related majors and courses of old people care services in institutions of higher learning and secondary vocational schools systematically[6].

Therefore, the real professionals engaged in the work of old people care are in dire need. It is urgent to explore various ways to cultivate nursing staffs, so as to solve the shortage of oldage nurse number. With the acceleration of population aging progress, the increase of social demands for old-age care professionals, except national attention to the pension problem, the increase of old people care nurse team of professional level can also promote these problems. Old-age nursing work will become a social need and meaningful career.

The old-age medical personnel training mode in colleges and universities changed the traditional composition and knowledge structure of medical staffs. Old-age care nurses are no longer just nannies taking care of old people's daily life, but professionals equipped with nursing knowledge, health care knowledge, professional ethics, laws and regulations of professional knowledge. As long as these meet the need of the venue and equipment standards, have enough faculty, standardized software and hardware conditions and zeal for old people care contributions, the Ministry of civil affairs vocational skills Appraisal Guidance centers are all for that. [8]. So medical colleges and universities should actively build endowment medical talent training conditions, which is an urgent need to establish "health care plus teaching" elderly institutions and the Internet care keeps integration of the new pension service mode. It plays an important role to explore more ways endowment the cultivation of the medical care personnel.

\section{Internet + medical integration talent training base building}

In order to keep pace with social and economic development and adapt to the trend of accelerating population aging, some cities have established a smart medical service model featuring the integration of medical treatment, nursing and elderly care. Information technology is used to integrate resources from related department. Based on bringing medical, nursery and rehabilitation service to each household, The model tailed to suit local conditions, can provide a continuous, comprehensive, effective and individualized health service which integrates medical treatment, nursery and health care into one[9]. From the above, construction of nursing talents team also should introduce the Internet concept and technology, which makes the nursing team a real one catering to the need of the Internet + age. We still have a long way to go to cultivate nursing talents of integration of medical treatment, nursing and elderly care so as to adjust to the demand of elderly care under different health conditions via integration of resources and innovation of mechanism under the current condition of limited resources and teaching system. Hence, we put forward ideas of Internet + talent training base construction for integration of medical treatment, nursing and elderly care. Talent training base mainly includes three modules: (1) the training base. There allocated simulated elderly intelligent apartment. It is equipped with demonstration room, elderly health lecture room, nurse training room, institute of geriatrics. There allocated health training platform system, the medical multimedia teaching and the teaching simulation teaching system and fully functional nursing standardized patients. 
Talents cultivating module provides theoretical and practical training platform. (2)health management demonstration center. There allocated rehabilitation training room. health data collection chamber (biochemistry checkout room, examination room apparatus), the elderly health service center (elderly drug monitoring guiding spot, psychological evaluation room) Health management module provides practice and service training platform. (3) the cloud platform. There allocated the information center (elderly health assessment, analysis, early warning systems), the call center training rooms. The cloud platform module provides information technology and cooperation of "enterprises, education and research institutes platform.

The cultivation of the nursing talents must innovate the teaching mode and develop the specialty groups in a coordinated way. Thus we could break through bottleneck of professional construction of nursing talents of integration of medical treatment, nursing and elderly care. The construction of the Internet + talent training base of integration of medical treatment, nursing and elderly care surely can push forwad the elderly care professional construction, playing a leading and exemplary role in the teaching mode. We should give great impetus to the "three-body system docking", which are the docking of the major setting and industry demands, the docking of curriculum content and occupational standard, the docking of the teaching process and the producing process seperately so as to realize an effective docking in the talent market. In order to provide recruting students, inetrnship and employment for vocational school students majoring in elderly care, "modularization" structure of the talent cultivation mode, namely, the combination of theory and practice, service and practice, infromation techology and cooperation of enterprises, education and research institutes, will develop the specialty groups in a coordinated way, propelling the construction and developing of related majors such as Clinical medicine, nursing, pharmacy, rehabilitation medicine and so on in the medical colleges.

\section{The function of Maintenance integration training base}

\subsection{Comprehensive training place for degree education personnel training}

The health care major opens up aging care courses, recruiting high school graduates, with 4- year schooling time. In the course, we set up the old age nursing, rehabilitation nursing, nutrition and nursing psychology courses to cultivate senior practical nursing talents who are morally, intellectually and physically developed, aged care -loving, respecting for the elderly, to respect, love and support for older people to implement the overall care, long-term care, hospice care, and basic ability of community health services, able to do a medical institution endowment and community endowment and home pension care. During the period of learning, students can strengthen themselves in the practical operation and highlight their professional skills through medical integration training platform.

\subsection{Providing service for standardization of vocational training}

Relying on professional university school of nursing, we carry out the qualification on students in pension caregivers (intermediate) . In accordance with the nursing professional talents cultivation orientation, combining with the national pension elderly national standard, comprehensive analysis has been courses in the nursing profession, adjusting the curriculum system setting, changing to the skilled nursing personnel training plan. According to national professional standards and national pension carer endowment, nurse training materials based nursing, medical nursing, surgical nursing care, emergency care, aged care, community nursing, nursing psychology, nutrition, diet, nursing humanities and nursing management, and other related content in the curriculum docking, it should be appropriately intensified or expanded. Such as rehabilitation nursing curriculum and the implementation of "academic qualification education + + function appraisal" integration of teaching mode so as to increase the source of the increasing pension medical staff team. For the notmentioned teaching content, we can supplement them through the way of conducting lectures. Such as professional ethics, laws and regulations (labor law), the old psychology, the old entertainment methods such as counseling lectures 


\subsection{Providing on-the-job personnel training conditions}

By forming medical treatment and care talent training base and using its unique advantages of teaching resources we can actively carry out in pension and medical institutions engaged in elderly medical and nursing staff professional training. To improve their professional skills, we can take going out and coming in method to organize expert teams carrying teaching molds to elderly institution to teach senile disease prevention knowledge and to train the employees of on-site operation.

\section{Integration nursing talents training base and nursing institutes rely on and support each other.}

Our institute and the Weiyang elderly welfare institution of Xi' an City have signed a cooperation agreement, which means through theoretical study and training on the integration nursing platform, our students will practice in the nursing institute.

Students go into the disability, half disability and self-care aera to provide multiple services for the old, such as blood pressure measuring, massage, conversation activities. Via these activities, students can easily find their shortages, improve the interest of mastery of professional technologies,

Enable them to increase their various skills in elderly care and have a direct understanding of the features of old people's health, psychology and daily life. It not only can deepen the care for the old but also can ease their loneliness. Teachers can find the questions lying in school teaching activities, seek out the disconnection part from the reality and provide ideas of improving teaching methods and content by leading the group practice activities. combining the actual conditions, it also provides contrent and a direction of scientific research. Teachers bearing related research projects can also fufill their scientific research projects by using the elderly care institutes ' resource.

On the other side, the talent construction of integration of medical care system training base can offer relative resources. The lower education background and the lack of standardization need to be trainned and properly operated. the medical care system training base can make full use of the sound resources of the school to provide theoretic and technical training for the nursing personel. We use the "going out " method to organize excellent teaching teams bearing teaching mould patterns to give the old people nurses trainning. Through on-site teaching, frequent demonstrations and teaching hand by hand, we keep doing until the students familarize the operation steps. The training base also organzie the volunteer activities for the old and publicize actively the health care knowledge with the help of the health managemnet center team, gaining wsrmly welcome from the old.

The integration nursing talents training base can provide the corresponding conditions for staffs of old-age nursing agencies. Both parties in university-enterprise cooperation will rely on and support each other. The talent training base becomes a bridge connecting the medical school and elderly institutions. Via this bridge, the connection and interaction of the two side is strengthened. they interact with each other in an overall way and benefits mutually. Talents training base cloud platform and oldage nursing institutions can also conduct data interaction via the Internet, and further carry out data sharing.

\section{The practice effect}

The students' employment channels have been broadened. With the help of medical integration base, the degree education has enhanced the school's reputation and recognition of professional teaching quality, and has cultivated a large number of old-age nursing professionals for local pension industry. At present, Old-age Nursing Institute of Union Hospital in Xi'an City has repeatedly discussed with our institute, and planned to recruit our students in batch to work in its institute. Some health management community centers also show their willings to employ our students in our school. Students also changed their concepts of traditional employment willing via the cultivating of the training 
base. They refresh the elderly care personel structure and deepen the willing to injoin the elderly care industry.

New way in the construction of old-age nursing team. According to the national standard, old-age nursing professional (intermediate) shall be trained for no less than 150 hours. Professional nursing courses have already basically covered and even surpassed the content related to nursing part in the old-aging nursing professional course. Besides, the medical integration training base has provided a good platform for the training. It can also improve the quality of the training staffs and standardize the opeeation steps. Therefore, for nursing students, they do not need to undertake much learning burden. And the training time which will be spent by nursing students to declare old-age nursing professional appraisal has been sharply reduced, and the training effect will be good.

Standard training for on-the-job personnel has also obtained good effect. We are actively engaged in training the old-age nursing professionals working in old-age institutions and medical institutions, and have enjoyed great reputation and praise and obtained good effect.

\section{6 discussion}

Internet with integrated medical support personnel training base for the community to build the culture of medical and nursing staff pension industry offers a modern training platform which promotes the conservation of the medical students' comprehensive integration of knowledge mastery, improves students' comprehensive ability and the quality of medical education significantly. It can be said playing a "three birds with one stone" effect. Aged care needs standardization, specialization and human services [10]. Regarding to how to achieve standardization and specialization of personnel requirements, innovative thinking should be actively sought to explore new ideas and initiatives nursing member team training. Internet with integrated medical support training base construction can provide a high standard of modern training platform for the community to train health care workers. Increasing social demands for nursing care professionals, in addition to the national attention on the pension problem and the professional level of the nursing member team improvement helps to get these issue gradually solved. The performing of colleges and universities Training Mode pension health care changed the composition and structure of the traditional knowledge of medical pension. For colleges which meet the space and equipment standards and standard hardware and software conditions and have a passion for the old-age care workers contribute to team building, Ministry of Civil Affairs Occupational Skill Testing Guidance Center encouraged for these situations [11]. In Medical Colleges, nursing member vocational qualification with a small cost, big return should be one of the important ways to nursing members of qualified personnel. Medical support integrated training base can make use of a large number of colleges and universities which have the basic knowledge of student resources, the strength of nursing teachers, standardized and modern training venue, thus improving the level of training, saving training costs, achieve "multiplier" effect.

Traditional nursing student employment scope is mainly limited in hospitals, community clinics. Medical and nursing students who have obtained qualifications in the medical school under the training of integration of health care system, can have broaden employment channels, especially for some private vocational high designed or secondary vocational school nursing students. It also has practical significance. For nursing students, in addition to nursing education license, nursing vocational qualification certificates, old-age care workers vocational qualification certificate, can choose the traditional areas of employment of nurses, nursing care can also choose the field of employment. At the same time, it avoids going into bottlenecks of a hard butting joint between the high cultivate a university-level specialized care service and pension service personnel and community. students can have a two-way selection and more freedom of choices of employment and the development of space will be more broad.

Medical support integrated training platform for students can not only promote the health of pension support comprehensive mastery of knowledge, but also significantly improve the quality of teaching. Meanwhile, the elderly and health care practitioner's vocational training pension industry provides a standardized platform for social pension and health care institutions to provide training for the social 
pension service. They also updated the concept of teachers teaching in medical colleges, improving the overall quality of teachers and optimizing teacher echelon construction.

We should seize opportunities, meet challenges, and train more high-level old-age care personnel teams. This is not only the prerequisite to improve the level of care service, but also an important guarantee for achieving the sustainable development of pension service.

\section{Conclusions}

In this paper, we clarify the concept of an Internet + talent training base of integration of medical treatment, nursing and elderly care and depicts the problems of old-aging society. Along with the accelerating aging of population, the old-aging support problem becomes increasingly prominent .With the global aging society, the demand of the global high-quality team of old-age care professionals is increasing. Therefore, we constructed an Internet + talent training base of integration of medical treatment, nursing and elderly care so as to provide a good platform for the students in medical schools with gerontology and geriatric nursing theory teaching and practical training, and it also put a great challenge in front of us. Internet + talent training base construction for integration of medical treatment, nursing and elderly care has been propelled by automatic medical services. Talent training base mainly consists of talent cultivation, health management and data processing, forming a nee platform for the cultivation of the nursing personel. The construction of the medicsl talents plays a significant part in meeting the increasing need of elderly care takents.

\section{Acknowledgment}

This work was supported by the Peihua special project Foundation of ShaanxiProvincial Government,2015.

\section{References}

[1] the ministry of civil affairs of the People's Republic of China. 2014 statistical bulletin social service development $\quad[\mathrm{EB} / \mathrm{OL}]$.

(2015-06-10)[2015-06-20]. http://www.mca.gav.cn/article/sj/tjgb/201506/20150608324399.shtml.)

[2] office of the state council. State Council's Opinions on Some Issues Concerning on speeding up pension services (guo fa [2013] no. 35) [R]. 2013.

[3] Shen Reling, chun-fang zheng jingjing. An aging population and the present condition of the elderly community care [J]. Journal of modern nursing, pp.1117-1119, 2007, 13 (12)

[4] yao lee. Australia endowment aspects of nursing care [J]. China medical personnel, pp. 68-70,2012, (03).

[5] Wang Jing guo-ping he. Elderly nursing human resources in China are faced with the problem and countermeasures. Care tuition, pp. 82-84, 2010, 25 (23) :.

[6] Huang Fei, Zhang Huijun XieJieMei. Old-age nursing staff training at home and abroad research progress [J]. Journal of nursing research, pp. 189-191,2011, 25 (1) late edition.

[7] Xu feng. Build long-term effective mechanism of systematic cracking pension talent crunch [J]. China's social welfare, pp. 46,2012, (12).

[8] the ministry of civil affairs vocational skills appraisal guidance centers. Looking back at 2011: pension nurse team construction and professional appraisal work adequately [J]. China's social welfare, 2012 (01). 
[9] Teng Jianrong, Zhou Zhilin, Zhou Hua, Establishing a smart medical service model featuring the integration of medical treatment, nursing and elderly care [J].Chinese Journal of Medical Management Sciences. pp. 23-26, January 2015, 1.5(1).

[10] Sun Yu Lin effect "Principles of Scientific Management" in resolving the skills shortage in the nursing care analysis. [J]. Social Welfare, pp. 60-64,2012 (12).

[11] MCA Occupational Skill Testing Center. Review of 2011: the nursing member team building and professional appraisal remarkable [J] China Social welfare,pp.8-9, 2012 (01). 